\title{
Stimulating entrepreneurship by introducing behavioural incentives. Propensity to use financial instruments in the context of decision makers' personal characteristics and their financial knowledge in Polish
} SMEs

\author{
Wojciech Bizon *
}

University of Gdansk , Gdansk, Poland

\author{
Index Terms \\ Entrepreneurship \\ SME \\ Behavioural economics \\ Financial knowledge \\ Framing
}

Received: 5 July 2016

Accepted: 10 October 2016

Published: 19 December 2016

\begin{abstract}
According to the observations of the support instrument market in Poland, one of the causes of the above-mentioned situation is the failure to adapt proposed instruments to the characteristics of SMEs, in particular ignoring the behavioral determinants in this group of businesses, including the behaviors based on another concept of economic rationality (different from the mainstream economics). Owing to empirical research, it has been possible to show that in Polish conditions, decision-makers in SMEs in specific conditions may be influenced by personal characteristics such as gender, education, seniority, experience, financial knowledge, and age. It can be expected that some of the personal qualities of decision-makers will contribute to either the acceptance or rejection of specific types of influences, which in turn may aid in the better presentation and tailor-making of instruments offered to support SMEs. As a consequence, such instruments should be offered differently depending on a specific recipient profile. Having in mind the practical dimension of conducted research analyses, at the Department of Macroeconomics, Faculty of Economics, University of Gdansk, Poland, several series of research were developed in 2013-16 aimed at separating groups of decision-makers in Pomeranian Small and mediumsized enterprises (SMEs) that will be susceptible to specific (differentiated) behavioral stimuli.
\end{abstract}

(C) 2016 The Author(s). Published by TAF Publishing.

\section{INTRODUCTION}

Small and medium sized enterprises (SMEs) play an important role in economies of numerous emerging economies. In Poland the SME sector employs more than $70.1 \%$ of labor force working in enterprises 2012 and contributes to more than $46.9 \%$ of GDP 2010 . The development of the SME sector could reach higher numbers but it is slowed down by underdeveloped financial sector services for SME. For example the debt of private sector in commercial banks reached 54.8\% in relation to GDP 2010, while in countries similar to Poland's GDP per capita: Malaysia $114.9 \%$, Estonia $97.2 \%$, Chile $86.3 \%$. Due to the fact that the financial sector is inefficient in delivering funds to SME, the important role in this area is played by regional policy, especially

${ }^{*}$ Corresponding author: Wojciech Bizon

†Email: w.bizon@ug.edu.pl 
supported by European funds. The majority of those funds are managed in Poland by autonomous regional authorities, however their distribution comes across as serious problem, because Polish SMEs are reluctant to use support instruments aimed at developing innovations, R\&D, and intellectual property protection.This fundamental issue of the relatively low efficiency of tools supporting the development of Polish SMEs in such areas as R\&D, intellectual property protection, the implementation of innovation etc. stems from the limited level of outlays on this purpose. However, the spending is not the only factor. According to the observations of the support instrument market in Poland, one of the causes of the above-mentioned situation is the failure to adapt proposed instruments to the characteristics of SMEs, in particular ignoring the behavioural determinants in this group of businesses, including the behaviours based on another concept of economic rationality (different from the mainstream economics).

A different perspective of processes that underlie the financial decision-making, as a new research issue, stems from the science of experimental and behavioural economics, initiated by Tversky \& Kahneman (1985) and developed in the 1980s. Two out of several important postulates of this alternative approach are as follows: questioning the classically understood rationality of a decisionmaker and omitting the profit maximization (utility) as a strict criterion of individual actions (Zaleśkiewicz, 2011). The topic of behavioral influences has become a part not only of theoretic considerations but of the economic and political practice as well, which resulted, among other, in the formulation of the concept of behavioral public interventions (BPI). The growing interest in behavioral economics is related to awarding the Noble Prize to (Gilovich, Griffin \& Kahneman, 2002; Akerlof, Michael \& Joseph, 1970). Behavioral economy is taught at all major universities, for example MIT, Stanford, Princeton, and Harvard, but is also present in academic teaching in the Central Europe, for example at the University of Gdansk and the Warsaw School of Economics. In 2009, George Soros donated USD 50 million to the establishment of the Institute for New Economic Thinking (INET), which focuses mostly on behavioral economics (Salvagno, 2013).

The practical importance of behavioral economics has been noted by OECD, which published a report entitled Regulatory Policy and Behavioral Economics (Lunn, 2014).The author of the report refers to examples of actions based on a behavioral concept of economics, which were implemented in recent years by the administration in the US, the
UK, Denmark, the Netherlands, and France. Interventions may take different forms - orders, prohibitions as well as information and awareness-raising campaigns. The objective of all such activities is to form a specific behavior that is to lead to desired effects. However, interventions do not always give the anticipated effects, which stem from the fact that to achieve such results, it is necessary to understand the mechanisms of human behavior and how people take their decisions (Shafir, 2013). Observing behaviours of entrepreneurs taking financial decisions has led not only to the separation of behavioural stimuli that determine a specific type of behaviour (e.g. framing), but also to creating recommendations on how to form available development instruments to make them an effective means of assistance for SMEs (Zaucha, 2011). Moreover, owing to empirical research, it has been possible to show that in Polish particular conditions choices made by decisions-makers in SMEs in specific conditions may be influenced by personal characteristics such as gender, education, experience (knowledge), seniority, and age (Bizon, 2011).

The assumption in the framing experiments carried out at the University of Gdansk was that the values of financial support for small businesses would be the same in the experimental and control groups. Framing would involve the provision of low-cost assistance in the form of consulting, information, training, etc. (forms of soft assistance), without modifying the financial value of an instrument. The achieved results were not explicit at all, and showed that friendly framing was sometimes counterproductive. The group of behavioural impacts consists of a broad range of differentiated stimuli that refer to such aspects, for example the above-mentioned framing, participation, benefit sharing, collective security, and consulting. It can be expected that some of the personal qualities of decision-makers will contribute to either the acceptance or rejection of specific types of influences, which in turn may aid in the better presentation and tailor-making of instruments offered to support SMEs.

As a consequence, such instruments should be offered differently depending on a specific recipient profile. Previous research conducted in Poland at the University of Gdansk in 2009-2011 showed the high dependence of the SMEs' propensity to use assistance tools in more challenging elements of business development, such as R\&D, innovation and patenting, on behavioral impacts, which make the offered instruments more friendly (framing). Such influences did not require any major increase of outlays on assistance. The research highlighted also that the readiness 
of SMEs to adapt specific assistance instruments is diversified, but some groups may be distinguished by similar behavioral types (e.g. from the perspective of the earlier use of the same type of instrument - financial knowledge, gender, and age). The latter finding resulted in formulating a recommendation that the entrepreneurship support policy may be differentiated and adapted to the special characteristics of different SME groups, i.e. segments of similar behavioral properties, in order to enhance its efficiency. This paper is based on research conducted by the University of Gdansk within the research conducted in 2013-2016. It was supported by the Polish National Center of Science in Cracow within the project: Impact of behavioral influences on absorption of development policy instruments by small and medium-sized enterprises (2012/07/B/HS4/02990).

\section{RESEARCH METHODOLOGY}

As a consequence of previous research, it has been finally proven that two factors determine the readiness to use financial instruments most, namely gender and work experience. In this study, a decision has been taken to replace the work experience with another factor that has not been analysed so far, which is the earlier experience of using a product (being in fact a sort of the financial knowledge). Therefore, the impact of framing depending on sex and earlier experience of using a specific financial support instrument has been subject to a more detailed analysis. Next, those two factors have become a starting point for the analysis within a decision-maker segmentation that has been created on an ad hoc basis.

As a consequence, four segments (groups) of receivers have been distinguished, which are characterised by a specific combination of personal characteristics.A behavioural experiment has been carried out to fulfil the above-mentioned objectives. As it has been mentioned above, the experiment has been a part of a broader project within behavioural economics, whose prime aim was to show the influence of behavioural determinants on decisions taken by SMEs.

Experimental simulations were based on quasiexperimental design described by Kulawczuk, Poszewiecki \& Bizon (2011) and fitted to the rules of psychological statistical methodology (Brzeziński, 2007). The research (in this part) was conducted among 200 entrepreneurs or representatives from the SME sector who used educational services of the University of Gdansk in years 2014-2015. The examined group was to be divided into two sub-groups of 100 respondents each that were to be presented with about 5 decision situations concerning the application of financial instruments offered to SME. The decision situations faced by the respondents involved:

1) Accepting a proposed incentive

2) A refusal to accept an incentive

3) A postponement of a decision for 3 months

4) A postponement of a decision for 6 months or

5) A postponement of a decision for one year

In relation to many other studies the research team decided to include the third category of decisions. Apart from YES/NO decisions we gave the opportunity not to make decision now and postpone it to some future moment: 3 months, 6 months and 1 year. It reflects typical business situations when entrepreneurs do not make decisions and wait for new information, examples of how situation changes and especially what are the results of the incentive for enterprises which took immediate positive decision. The study took account of the time factor, as Polish small and medium enterprises often avoid taking a decision and postpone it.

For several instruments, decision situations were formulated as a trade-off issue or as the assessment of preferences (for the assessment of the tendency to cooperate in risk conditions and for positive measures). Each of the sub-groups, although they were usually offered the same instruments, had different framing of their use. Framing means that despite the basically identical content (with several explicitly marked exceptions), the method of communicating or offering an instrument varied. The authors assumed based on conclusions of Tversky \& Kahneman (1985) that the framing of the public assistance incentives or the framing of commercial financial instruments offered to SME may have a material impact on the propensity to use such financial incentives.

The used behavioural stimuli had different forms; however, they all had the characteristics close to the framing concept. It is noteworthy that the 'power' of a stimulus differed, which means that depending on a decision situation, the introduction of a specific behavioural stimulus changed the impact of an offer to a varied degree. The following offer modification methods have been applied:

- Determining (anchoring) a cap for an own contribution (1st question)

- Information on free-of-charge consulting and instruction (2nd and 4th questions)

- A suggestion of the best solutions (3rd question)

- Emphasizing the facilitation and flexibility of procedures (5th question) 
The objective of the study was to determine if the introduction of framing (as described above) contributes in general and in specific groups to the higher average acceptance of an instrument. Therefore, the following study question was asked: what is the impact of framing on each of the distinguished segments? Apparently, the question refers to the influence of framing within specific groups. This part of the study will be dedicated, therefore, to answering questions that concern the effect of framing depending on different personality characteristics and professional experiences of a decision-maker. Due to the distribution of answers, which are far from standard, and the large sample, the nonparametric statistical test of Kolmogorov-Smirnov has been utilised as an auxiliary tool to support this part of the analysis. As a result, two questionnaires were formulated with different framing within the experimental simulation.

The different framing was defined as either typical or friendly. The typical framing reflected standard Polish reality in offering financial incentives for SME, while the friendly framing included additional non-financial elements, which according to the authors were to increase the assimilability of the incentives. To avoid accusations of bias in the specific versions of the questionnaire (a typical accusation against framing research) it was decided that each subgroup would have decision situations with both friendly and typical conditions. Therefore, every subgroup had decision situations with typical framing and with friendly framing, however in different questions. Respondents representing small and medium enterprises from the northern and seaside Pomeranian Region in Poland were selected for the research. A team of pollsters contacted representatives of enterprises, mostly personnel of business-economic departments as well as managers and owners of SME who used educational services in years 2014-2015 (in different forms of adult learning.

Half of the randomly selected persons received research questionnaires of the typical version, while the other half received the questionnaires in the friendly version. The method was based on the random unlimited sampling of respondents to each group. Every drawn entrepreneur received one questionnaire to be completed by the management staff. Overall, 100 completed questionnaires in each subgroup were collected. Respondents gave answers to the questions containing issues concerning entrepreneur behavior (i.e. how they would behave in a situation) spontaneously. This type of research is called experimental simulation. They were asked to take a decision as if they were to take a decision alone and immediately, which was a considerable simplification. In actual operation of SME, financial decisions are generally taken as a result of analyses and consultation that may take hours or days. However, it is to be emphasized that decisions whether an instrument or a market opportunity are interesting from the point of view of a firm, are worth dedicating time to and are taken quickly. According to observations, if a subject matter is considered to be important for an enterprise, it is usually continued. The research involved experimental simulation, which implies that it is not known if both groups would take the same decisions in real life as in the experimental simulations.

It was assumed, however, that the readiness to cheat (or change decisions) did not differ depending on belonging to a control or experimental group (it was assumed to be identical in both groups). So the simulation showed realistic differences and the impact of intervention. The similarity of both groups was verified with statistical methods. The verified elements included the similarity of structures, distribution covariance, medium and standard deviations, kurtoses and the inclination of distribution. Moreover, the hypothesis of tests (groups) similarity was verified with the Smirnov-Kolmogorov test. The Smirnov-Kolmogorov tests were applied to analyze the similarities of continuous variable distributions characteristic for the respondents, such as age, job seniority and the period of work in finance.

The tests showed that both groups came from the same population and the differences between the distributions of important properties that characterized respondents were not statistically significant. Hence, it has been assumed that two factors determine the readiness to use financial instruments, namely: gender and previous experience of using a product (or products of similar characteristics). By assuming these two determinants as the criteria for the decisionmaker segmentation, four separable (independent) groups have been obtained:

- $[\mathrm{WE}]$ - women with experience of using a financial instrument

- $[\mathrm{WN}]$ - women without experience of using a financial instrument

- $[\mathrm{ME}]$ - men with experience of using a financial instrument, and

- $[\mathrm{MN}]$ - men without experience of using a financial instrument

Considering the conditions related to adopting specific segmentation criteria and the results of tests concerning separately the treatment of gender and experience aspects 
in the use of specific support instruments, the following research hypothesis has been formulated:

H1: Out of the separated segments of decision-makers, the readiness to change decisions and the tendency to approve a tool as a result of introducing a specific behavioural stimulus are most visible in the segment of women who have had no previous experience of using a tool (WN segment).

\section{RESULTS}

A starting point is to determine the level of participation (the readiness to use a financial instrument) in each segment with the assumption of a typical market offer. Next, the analogous values have had to be determined in a situation where respondents have been presented a modified offer, which takes into account a behavioural stimulus. The compared values were both the average (measured with the Likert scale) as well as the percentage of persons who declared their immediate acceptance of a tool. Tables 1-4 present the relevant data. The column 'average - a typical option' shows the average obtained for data expressed in the Likert scale from 1 to 5 , where the higher value means the higher readiness to accept immediately the offer that has been presented in a typical option. On the other hand, the column 'average - a modified option' presents an analogous value, but referring to an offer that contains framing. The last two columns include the percentage of persons from a segment who have declared their willingness to use a specific instrument - in the typical and modified versions respectively.

TABLE 1. Reaction of women holding experience of using an instrument to a change of a decision situation in the studied issues in consecutive decision situations (WE segment)

\begin{tabular}{|c|c|c|c|c|c|}
\hline No & $\begin{array}{l}\text { Average } \\
\text { a typical }\end{array}$ & $\begin{array}{l}\text { Average a } \\
\text { modified }\end{array}$ & $\mathbf{p}$ & $\begin{array}{l}\text { Percentage } \\
\text { of immediate } \\
\text { acceptance }\end{array}$ & $\begin{array}{l}\text { Percentage } \\
\text { of immediate } \\
\text { acceptance }\end{array}$ \\
\hline & option & option & & $\begin{array}{l}\text { [a typical } \\
\text { option] }\end{array}$ & $\begin{array}{l}\text { [a modified } \\
\text { option] }\end{array}$ \\
\hline 1 & 4.900000 & 4.714286 & $p>.10$ & 90.00 & 78.57 \\
\hline 2 & 4.000000 & 3.967742 & $p>.10$ & 53.85 & 58.06 \\
\hline 3 & 4.193548 & 4.029412 & $p>.10$ & 64.52 & 67.65 \\
\hline 4 & 3.434783 & 3.260870 & $p>.10$ & 52.17 & 47.83 \\
\hline 5 & 3.480000 & 3.190476 & $\mathrm{p}>.10$ & 40.00 & 42.86 \\
\hline
\end{tabular}

TABLE 2 . The reaction of women having no experience of using an instrument to a change of a decision situation in the studied issues in consecutive decision situations (WN segment)

\begin{tabular}{lllcll}
\hline \hline & $\begin{array}{l}\text { Average } \\
\text { a typical } \\
\text { option }\end{array}$ & $\begin{array}{l}\text { Average a } \\
\text { modified } \\
\text { option }\end{array}$ & $\mathbf{p}$ & $\begin{array}{l}\text { Percentage } \\
\text { immediate } \\
\text { acceptance } \\
\text { [a typical } \\
\text { option] }\end{array}$ & $\begin{array}{l}\text { Percentage } \\
\text { immediate } \\
\text { acceptance } \\
\text { [a modified } \\
\text { option] }\end{array}$ \\
\hline 1 & 4.109091 & 4.180000 & $\mathrm{p}>.10$ & 63.64 & 60.00 \\
2 & 3.384615 & 3.636364 & $\mathrm{p}>.10$ & 38.46 & 39.39 \\
3 & 4.030303 & 4.387097 & $\mathrm{p}>.10$ & 63.64 & 77.42 \\
4 & 3.214286 & 3.707317 & $\mathrm{p}>.10$ & 45.24 & 58.54 \\
5 & 2.794872 & 3.500000 & $\mathrm{p}<.01$ & 7.69 & 45.45 \\
\hline \hline
\end{tabular}


TABLE 3 . Reaction of men holding experience of using an instrument to a change of a decision situation in the studied issues in consecutive decision situations (ME segment)

\begin{tabular}{|c|c|c|c|c|c|}
\hline No & Average a typical option & Average a modified option & $\bar{p}$ & $\begin{array}{l}\text { Percentage of imme- } \\
\text { diate acceptance [a } \\
\text { typical option] }\end{array}$ & $\begin{array}{l}\text { Percentage of imme- } \\
\text { diate acceptance [a } \\
\text { modified option] }\end{array}$ \\
\hline 1 & 4.100000 & 5.000000 & $\mathrm{p}>.10$ & 60.00 & 100.00 \\
\hline 2 & 4.538462 & 4.812500 & $\mathrm{p}>.10$ & 69.23 & 81.25 \\
\hline 3 & 4.050000 & 4.142857 & $\mathrm{p}>.10$ & 75.00 & 66.67 \\
\hline 4 & 3.833333 & 3.058824 & $\mathrm{p}>.10$ & 66.67 & 47.06 \\
\hline
\end{tabular}

TABLE 4 . A reaction of men having no experience of using an instrument to a change of a decision situation in the studied issues in consecutive decision situations (MN segment)

\begin{tabular}{|c|c|c|c|c|c|}
\hline No & Average a typical option & Average a modified option & $\mathbf{p}$ & $\begin{array}{l}\text { Percentage of imme- } \\
\text { diate acceptance [a } \\
\text { typical option] }\end{array}$ & $\begin{array}{l}\text { Percentage of imme- } \\
\text { diate acceptance } \\
\text { modified option] }\end{array}$ \\
\hline 1 & 4.120000 & 4.318182 & $\mathrm{p}>.10$ & 72.00 & 72.73 \\
\hline 2 & 3.818182 & 4.550000 & $\mathrm{p}>.10$ & 54.55 & 75.00 \\
\hline 3 & 3.687500 & 3.357143 & $\mathrm{p}>.10$ & 50.00 & 57.14 \\
\hline 4 & 3.217391 & 3.684211 & $\mathrm{p}>.10$ & 47.83 & 47.37 \\
\hline
\end{tabular}

To make it easier to give answers to the question if and how a change of a decision situation affects the readiness to become interested in a financial instrument depending on a studied segment, the results have been presented in table 5. The columns show a specific decision situation together with a type (description) of an applied stimulus. The differences in the average level of instrument acceptance (i.e.in the situation before and after the introduction of a stimulus) as well as the observed changes of the level of declared immediate use of an instrument have been presented.

A general assessment of changes for each segment has been presented as a finding in a five-level scale (highly positive/positive/neutral/negative/highly negative). The general assessment of changes has been presented in a description, however only after an attempt at making the results obtained in the study objective. It has been assumed based on a simple algorithm that the result that is subject to assessment will be obtained as the total product of a number 25 (according to the adopted five-point Likert scale, which in fact assumes five ranges) and the difference recorded in the level of average acceptance (the first element of the total) and the difference in the declared level of immediate use (the second element of the sum). The obtained value has been referred to the scale: below -15 - a highly negative reaction; from -15 inclusive to -5 - a negative reaction; from -5 inclusive to 5 inclusive - a neutral reaction; above 5 to 15 inclusive - a positive reaction; and more than $15-\mathrm{a}$ highly positive reaction.While analysing the general assessment of changes among the diversified groups (subjected to segmentation) according to the table due to the sex and experience of using a support instrument, a question may be answered if and to what extent a change of a decision situation affects the readiness to become interested in a financial instrument.

In the WE segment (women with experience of using a financial product), the introduction of an additional behavioural stimulus will not give any positive results. Neutral reactions prevail (tree-times), with the simultaneous occurrence of highly negative reactions. A completely different reaction has been recorded in the WN segment (women without experience of using an instrument). In this group, the highly positive reactions occurred twice, and a neutral reaction once. In the group of men having experience of the use of a financial instrument (ME), reactions were highly diversified. Two of the five stimuli resulted in positive and highly positive reactions, while three other gave a negative result.The $\mathrm{MN}$ segment (men without any experience of using an instrument) was dominated by positive reactions (three times). Very positive and neutral reactions occurred once. 
TABLE 5 . A general reaction to a change of a decision situation in specific segments

\begin{tabular}{|c|c|c|c|c|c|c|}
\hline & & 1 & 2 & 3 & 4 & 5 \\
\hline \multirow[t]{2}{*}{ segment } & Question & $\begin{array}{l}\text { An auction for an own } \\
\text { contribution with sub- } \\
\text { sidies for SME develop- } \\
\text { ment projects }\end{array}$ & $\begin{array}{l}\text { A typical credit from a } \\
\text { commercial bank guar- } \\
\text { anteed by BGK - Domes- } \\
\text { tic Economy Bank }\end{array}$ & $\begin{array}{l}\text { The development or- } \\
\text { ganic credit to support } \\
\text { regular savings }\end{array}$ & $\begin{array}{l}\text { Capitalization with the } \\
\text { public venture capital } \\
\text { fund }\end{array}$ & 0n-line credit \\
\hline & Behavioural stimulus & $\begin{array}{l}\text { Determining (anchor- } \\
\text { ing) a cap for an own } \\
\text { contribution }\end{array}$ & $\begin{array}{l}\text { Information on free-of- } \\
\text { charge consulting and in- } \\
\text { struction }\end{array}$ & $\begin{array}{l}\text { Framing: a suggestion of } \\
\text { the best solutions }\end{array}$ & $\begin{array}{l}\text { Information on free-of- } \\
\text { charge consulting and in- } \\
\text { struction }\end{array}$ & $\begin{array}{l}\text { Emphasizing the facili- } \\
\text { tation and flexibility of } \\
\text { procedures }\end{array}$ \\
\hline WE & $\begin{array}{l}\text { A change of the declared } \\
\text { immediate use of an in- } \\
\text { strument }\end{array}$ & -11.43 & 4.21 & 3.13 & -4.34 & 2.86 \\
\hline \multirow[t]{3}{*}{ WN } & $\begin{array}{l}\text { An average level of instru- } \\
\text { ment acceptance (before / } \\
\text { after the introduction of a } \\
\text { stimulus) }\end{array}$ & 0.07 & 0.28 & 0.36 & 0.50 & 0.71 \\
\hline & $\begin{array}{l}\text { A change of the declared } \\
\text { immediate use of an in- } \\
\text { strument }\end{array}$ & -3.64 & 0.93 & 13.78 & 13.30 & 37.76 \\
\hline & $\begin{array}{l}\text { The general assessment of } \\
\text { changes (highly positive / } \\
\text { positive / neutral / nega- } \\
\text { tive / highly negative) }\end{array}$ & neutral & positive & positive & highly positive & highly positive \\
\hline ME & $\begin{array}{l}\text { The general assessment of } \\
\text { changes (highly positive / } \\
\text { positive / neutral / nega- } \\
\text { tive / highly negative) }\end{array}$ & highly positive & positive & negative & highly negative & negative \\
\hline \multirow[t]{3}{*}{ MN } & $\begin{array}{l}\text { An average level of instru- } \\
\text { ment acceptance (before / } \\
\text { after the introduction of a } \\
\text { stimulus) }\end{array}$ & 0.20 & 0.73 & -0.33 & 0.46 & 0.24 \\
\hline & $\begin{array}{l}\text { A change of the declared } \\
\text { immediate use of an in- } \\
\text { strument }\end{array}$ & 0.73 & 20.45 & 7.14 & -0.46 & 17.27 \\
\hline & $\begin{array}{l}\text { The general assessment of } \\
\text { changes(highly positive / } \\
\text { positive / neutral / nega- } \\
\text { tive / highly negative) }\end{array}$ & positive & highly positive & neutral positive & positive & \\
\hline
\end{tabular}


TABLE 6. A type of reaction to a decision situation for specific segments of decision makers

\begin{tabular}{|c|c|c|c|c|c|}
\hline & 1 & 2 & 3 & 4 & 5 \\
\hline $\begin{array}{l}\text { A decision situa- } \\
\text { tion }\end{array}$ & $\begin{array}{l}\text { An auction for an } \\
\text { own contribution } \\
\text { with subsidies for } \\
\text { SME development } \\
\text { projects }\end{array}$ & $\begin{array}{l}\text { A typical credit } \\
\text { from a commer- } \\
\text { cial bank guar- } \\
\text { anteed by BGK- } \\
\text { Domestic Econ- } \\
\text { omy Bank }\end{array}$ & $\begin{array}{l}\text { The development } \\
\text { organic credit to } \\
\text { support regular } \\
\text { savings }\end{array}$ & $\begin{array}{l}\text { Capitalization } \\
\text { with the public } \\
\text { venture capital } \\
\text { fund }\end{array}$ & On-line credit \\
\hline \multicolumn{6}{|l|}{ Reaction } \\
\hline Highly positive & $\mathrm{ME}$ & $\mathrm{MN}$ & & $\mathrm{WN}$ & WN \\
\hline Highly negative & WE & & & $\mathrm{ME}$ & \\
\hline
\end{tabular}

The above findings lead to the conclusion that out of the separated segments of decision-makers, the readiness to change a decision and to concentrate it on the acceptance of an instrument as a result of introducing a specific behavioural stimulus is most visible in the segment of women who have had no previous experience of using an instrument, which leads to the observation that $\mathrm{H} 1$ may be considered to be proven. While continuing the analysis of observed reactions to a change of a decision situation in specific segments, reactions may be grouped depending on a type of a decision situation and thus an applied stimulus. The details have been presented in table 6 .

Collective findings related to a reaction to a change of a decision situation in specific segments of decision-makers are as follows:

1. The introduction of a cap has a strong positive impact on men (especially strong on men having experience of using similar instruments). At the same time, a strong negative reaction has been observed among women with an analogous experience.

2. Information on the free-of-charge instruction and consulting (in case of a typical credit guarantee) has a strong positive influence on the segment of men without any experience of using similar instruments, a positive influence on the group of women without any experience, and a group of men holding experience. No negative reactions have been recorded for this stimulus.
3. The use of framing expressed as a suggestion of best solutions has led to a positive reaction only in the segment of women without any experience. A negative reaction has been also recorded in the group of men with experience in using an instrument.

4. Information on free consulting and instruction (in the option concerning the capitalization with a public venture capital fund) has resulted in the highly positive reaction among women with experience and a positive reaction in an analogous group of men. In groups of respondents with experience of the examined scope, a highly negative reaction (men) and a negative reaction (women) have been recorded.

5. The use of a stimulus determined as stressing the facilitation and flexible procedures has resulted in a highly positive reaction in the group of female respondents having no experience and in a positive reaction in the group of men without any experience. A negative reaction occurred in the segment of men holding experience.

To sum up the analysis related to the impact of introducing specific behavioural stimuli on decisions of respondents in each of the separated segments, recommendations may be put forward that concern the question formulated as follows: "how to use a stimulus and which stimuli to avoid in specific segments, to obtain a higher participation level and thus the use of a specific financial instrument?'. Table 7 presents the collective recommendations in this respect. 
TABLE 7. A type of reaction to a decision situation for specific segments of decision makers

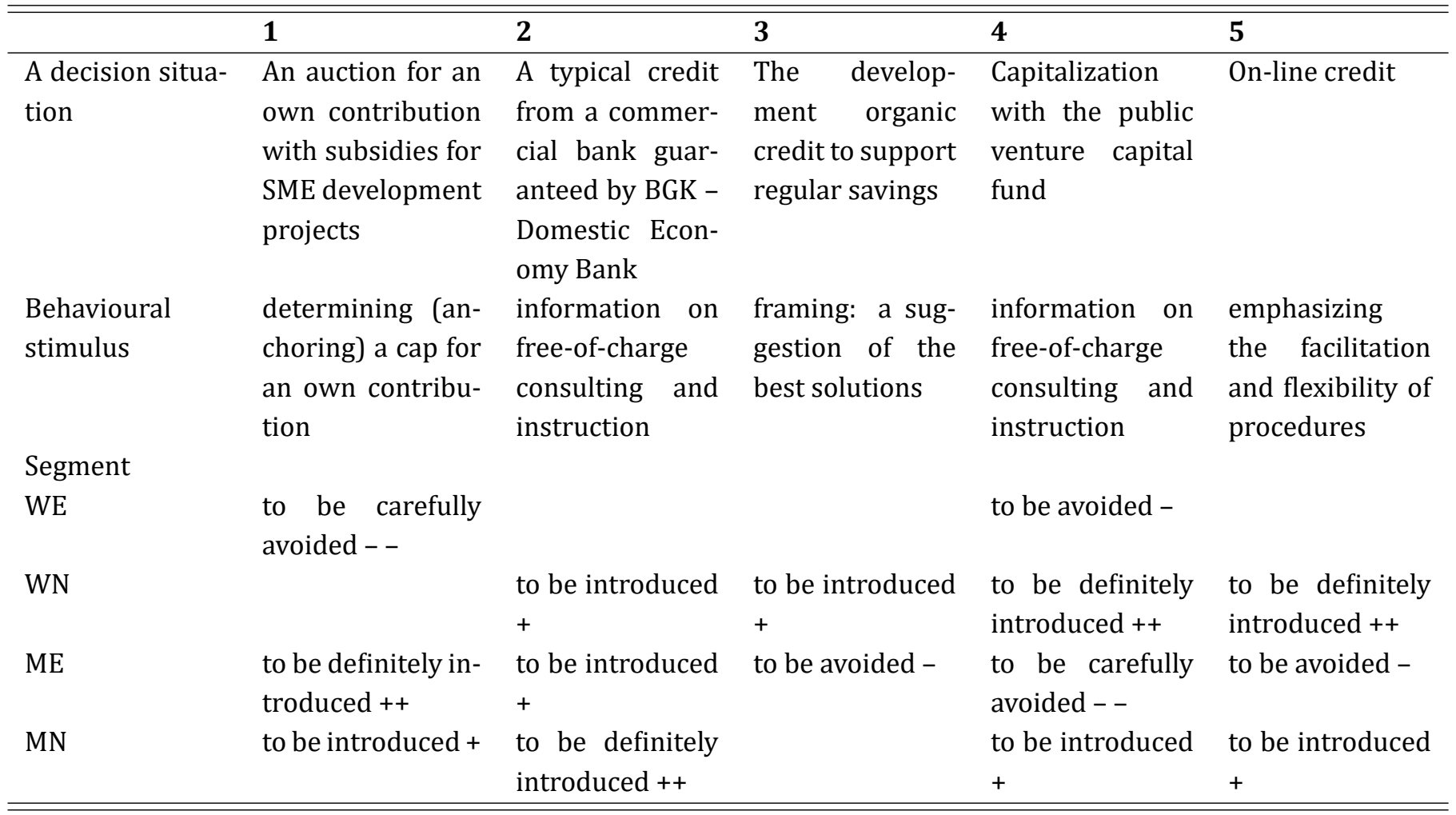

\section{DISCUSSION AND CONCLUSION}

It can be noted that the introduction of a specific type of a behavioural stimulus should be recommended first of all in the group of women who have not experienced a solution before. Similar findings (although not as strong) have been recorded for the male group of respondents. It is worth mentioning that a contrario a segment of women having experience of using tested tools is least positively susceptible to the type of framing described in the study. Therefore, a careful approach should be adopted to implementing universal solutions that are not sufficiently profiled to the needs of such respondents. Summing up, it has to be stated that despite the relatively detailed analyses and precise results, it can be suspected that only the multiple anal- ysis of numerous similar stimuli used in decision situations that are as close as possible to the actual needs of decisionmakers in the SME sector will make it possible to describe the effects of changes more comprehensively and to assess the differences between a typical and an ideal situation and to study even better the specific segments. Therefore, it should be recommended that in the further studies a specific segment is to be focused on and several stimuli should be tested that may refer to a specific decision situation. Owing to this approach, it will be possible to obtain a broader spectrum of knowledge about the segments of decision makers in small and medium enterprises that are most interesting from the perspective of the entrepreneurship support policy.

\section{REFERENCES}

Akerlof, G., Michael, S., \& Joseph, S. 1970. Markets with asymmetric information. URL: goo.gl/ycrvhJ. Last accessed on 12 August 2016.

Bizon, W. 2011. Propensity to use financial instruments depending on education, gender, age, seniority, and experience in finance. In P. Kulawczuk, A. Poszewiecki, \& W. Bizon (Eds.), Behavioral finance of entrepreneurship. How can framing influence financial decisions of entrepreneurs? Gdańsk, Poland: University of Gdansk.

Brzeziński, J. 2007. Methodology of psychological research. Warszawa, Poland: PWN Publisher.

Gilovich, T., Griffin, D., \& Kahneman, D. 2002. Heuristics and biases: The psychology of intuitive judgment. Cambridge, UK: Cambridge University Press. DOI: 10.1017/CB09780511808098 
Kulawczuk P., Poszewiecki A., \& Bizon W. 2011. Behavioral finance of entrepreneurship: How can framing influence financial decisions of entrepreneurs? Gdańsk, Poland: University of Gdansk.

Lunn, P. 2014. Regulatory policy and behavioural economics. Paris, FR: OECD Publishing.

Salvagno, M.J. 2013. Economists on the 2008 financial crisis: Genuine reflection; or constructing narratives to reaffirm the profession's authority? In J. Jespersen \& M.O. Madsen (Eds.), Teaching post keynesian economics, Northampton, MA: Edward Elgar Publishing. DOI: 10.4337/9781782547006.00018

Shafir, E. 2013. The behavioral foundations of public policy. New Jersey, NJ: Princeton University Press.

Tversky, A., \& Kahneman, D. 1985. The framing of decisions and the psychology of choice. V.T. Covello, J.L. Mumpower, P. J.M. Stallen \& V. R.R. Uppuluri (Eds.), Environmental Impact Assessment, Technology Assessment, and Risk Analy- sis. Berlin, DE: Springer Berlin Heidelberg. DOI: 10.1007/978-3-642-70634-96

Zaleśkiewicz, T. 2011. Economic psychology. Warszawa, Poland: PWN.

Zaucha, J. 2011. Conclusions on experimental simulations concerning SME financial decision making: Recommendations for public policy. In P. Kulawczuk, A. Poszewiecki \& W. Bizon (Eds.), Behavioral finance of entrepreneurship. How can framing influence financial decisions of entrepreneurs? Gdańsk, Poland: University of Gdansk.

— This article does not have any appendix. — 